\title{
SOBRE LA TEORÍA \\ DE LA DEMOCRACIA \\ Y EL CONCEPTO \\ DE REPRESENTACIÓN POLÍTICA: \\ ALGUNAS PROPUESTAS \\ PARA DEBATE
}

\begin{abstract}
a presencia del mecanismo institucional de la representación política en todas las sociedades democráticas conocidas ha sido explicada y justificada desde siempre mediante una argumentación canónica que, seguramente por su aparente trivialidad, apenas se ha cuestionado. Uno de los propósitos de este trabajo es sugerir que podría hacerse. Por otro lado, la noción misma de «representación» ha sido sometida a un detenido examen analítico y los resultados de ese examen han disipado muchas confusiones, pero también han abierto incógnitas nuevas. En la segunda parte me ocuparé de algunas de ellas. En cualquier caso el tema es complejo y debatido y la intención de estas páginas sólo es ponerlo de manifiesto para estimular la discusión en torno a él.
\end{abstract}

\section{I}

La justificación de la democracia representativa se ha realizado secularmente mediante una fórmula arquetípica que parece haberse incorporado al acervo de los tópicos políticos comunes. Así la expresaba Montesquieu: «Puesto que en un Estado libre todo hombre, considerado como poseedor de un alma libre, debe gobernarse por sí mismo, sería preciso que el pueblo en cuerpo desempeñara el poder legislativo. Pero como esto es imposible en los grandes Estados, y como está sujeto a mil inconvenientes en los pequeños, el pueblo deberá realizar por medio de sus representantes lo que no puede hacer por sí mismo.» Un siglo después lo hacía así John Stuart Mill: «Según las consideraciones antedichas, es evidente que el único gobierno que satisface por completo todas las exigencias del estado social es aquel en el cual tiene participación el pueblo entero... Pero puesto que en toda comunidad que exceda los límites de una pequeña población 
nadie puede participar personalmente sino de una porción muy pequeña de los asuntos públicos, el tipo ideal de un gobierno perfecto es el gobierno representativo.» Y por último, en el siglo XX, Hans Kelsen lo afirmaba así: "Cuanto más grande es la colectividad política, tanto menos capaz se muestra el "pueblo", como tal, de desenvolver la actividad creadora de la formación directa de la voluntad política, y tanto más obligado se ve -aunque sólo fuese por razones técnicosociales- a limitarse a crear y controlar el verdadero mecanismo que forma la voluntad política.»

Estas tres posiciones comparten una cláusula común. La imposibilidad material de participación de todos en la elaboración de las normas generales debida al tamaño físico de la colectividad. Pero parten de fundamentos distintos. Montesquieu arranca de la noción de «alma libre» que se gobierna a sí misma; es decir, del principio ético de autonomía. Mill, por su parte, apoya más su opción en la participación de todos los intereses en la elaboración de la decisión. Ambos suponen, sin embargo, que la transición de la presencia directa de todos en la decisión a la presencia solamente de los representantes no invalida la justificación última de la institución. Kelsen, por el contrario, afirma que esa transición supone una cierta ruptura con el ideal de libertad política, pero alega la ineludible necesidad técnica de división del trabajo social para defender el parlamentarismo representativo como fórmula estable de articulación del Estado. Al margen de la mayor complejidad de la aportación de cada uno de ellos y de los matices y variantes (a veces importantes) que introducen en sus enfoques podemos tomar estas aproximaciones como modelos ad hoc de un razonamiento que se desarrolla en tres fases. 1) Justificación de la presencia de todos en la decisión (autonomía, interés, paz social). 2) Cláusula de imposibilidad, y 3) por tanto, necesidad del mecanismo de la representación. El núcleo de este razonamiento es que el modelo ideal de organización política sería la democracia directa, pero como se da la cláusula de imposibilidad, tenemos que desembocar en la aceptación de la democracia representativa como forma menor o atenuada, como sucedáneo posible, del modelo ideal. La representación, por tanto, tendría en el mejor de los casos, una justificación «derivada» y no una justificación originaria y propia, y encontraría su perfil y naturaleza precisamente en el eco que le llega de aquella justificación primaria después de pasar por el tamiz de la cláusula de imposibilidad.

La plausibilidad de esta argumentación descansa sin duda en la suposición de que el deslizamiento que se opera desde la decisión 
tomada por todos a la decisión tomada por representantes no hace necesario modificar la justificación. O lo que es lo mismo, que el tipo de justificación procedimental o sustantiva de la decisión de todos se traslada a la decisión de representantes. Esto, sin embargo, es altamente controvertible. Tanto que quizá sería prudente asumir que no es así, con lo cual podríamos encontrarnos frente a un problema serio: cualquiera que sea la justificación de la democracia directa, la cláusula de imposibilidad determina que no sea aplicable a la democracia representativa. Para resolver ese problema es necesario construir una justificación autónoma para la democracia representativa que no sea producto de un mero deslizamiento a partir de la otra. Las sugerencias que siguen sólo pretenden animar la controversia en esa dirección.

Cualquiera que haya frecuentado la literatura filosófica actual sobre la justificación de la democracia habrá advertido inmediatamente que en su gran mayoría se sustenta sobre una presuposición tácita en torno a la naturaleza del grupo social humano. $\mathrm{O}$, para expresarlo de otro modo, que construye su argumentación sobre un modelo determinado de grupo social humano. Este modelo tácito, o esa presuposición, consiste en concebir al grupo como un colectivo desagregado de unidades que, en un momento determinado, «se proponen» constituir una asociación o tomar una decisión común. Los ejemplos son numerosos. Dahl inicia así uno de sus ensayos: «Déjenme empezar por asumir que cada uno de un cierto número de personas tiene en mente la idea de formar una asociación para ciertos propósitos, o de cambiar una asociación ya existente...» (Dahl, 1979.) Farrell, recientemente: «Quiero examinar un caso en el cual ciertos individuos deben elegir una forma determinada de gobierno al haber decidido vivir en sociedad.» (Farrell, 1988, pág. 11.) También Singer, que arranca de un «modelo simplificado» como es el senior common room de un college universitario (Singer, 1985). No creo que sea exagerado afirmar que una presuposición metódica semejante late en muchas de esas aportaciones. Y lo que quisiera sugerir es que eso puede ser algo que dificulte innecesariamente la tarea de enfocar el problema de la representación política $\mathrm{y}$, en consecuencia, de la democracia representativa. El tipo de modelo hipotético que utilizan como punto de partida para hacer sus propuestas normativas puede llevar consigo limitaciones propias que le impidan alcanzar la cuestión real que se proponen resolver.

Me parece que el punto de partida no puede ser que unos cuantos individuos aislados «decidan» asociarse, porque en ese 
caso habremos limitado el alcance del modelo de tal forma que sirve únicamente para reflexionar sobre criterios propios de un club, una cofradía o una tertulia, y aun eso con ciertas limitaciones. El punto de partida tendría que ser más bien un modelo de grupo humano menos contingente y unilateral, es decir, más cercano al tipo de grupo donde los individuos desarrollan su vida y sus experiencias personales generales. Ahora bien, cuando iniciamos cualquier reflexión sobre la naturaleza de esos tipos generales de grupos humanos caemos inmediatamente en la cuenta de que no se trata de agregados inconexos de individuos portadores de deseos, preferencias y planes de vida, aunque en el seno de tales grupos existan, en efecto, tales individuos. Los grupos son conjuntos, cuyos componentes individuales están ligados entre sí por pautas y directrices comunes que se manifiestan en esquemas de interacción y coordinación que limitan y modulan las conductas individuales. Para que el grupo exista (y el grupo es algo que existe tanto como el individuo) es necesario que se den ciertas reglas que gobiernan las interacciones de forma tal que pueda predecirse razonablemente cuál va a ser el comportamiento de los demás en aspectos relevantes. «Las interacciones recíprocas de las personas llevarán a todos o a la mayoría a conformarse a ciertas convenciones de coordinación y a esperar de otros, y saber que ellos esperarán de uno mismo, que se conformen a ellas.» (Honoré, 1975.) Estas expectativas pautadas de conducta son imprescindibles no sólo para la inserción personal, sino también para el propio desarrollo individual, y, como escribe Honoré, son «la característica definitoria del grupo». La interacción humana pautada mediante convenciones es lo que define en los términos más elementales al grupo social. Cuando hablamos de individuos humanos no hablamos de puras «unidades», sino de individuos o seres que, como decía Ferguson en su clásica obra, siempre han errado o se han asentado «en tropel y compañía».

Aunque todas estas afirmaciones son elementales, y dudo mucho que nadie pueda discutirlas, convendrá sin embargo tomar cuanto antes la precaución de ubicarlas correctamente en las coordenadas de la actual polémica entre el liberalismo y el comunitarismo (Nino, 1988) para precisar su intención y alcance. El liberalismo es una filosofía moral individualista. Pero «individualismo» es una expresión que tiene al menos tres usos teóricos diferentes. Hay un individualismo «metodológico» que pretende que las decisiones colectivas son una función de, o pueden ser interpretadas en términos de, las decisiones individuales. Hay un individualismo «ontológico» que pretende que la 
realidad humana sólo es definible como agregado de individuos separados. Y hay un individualismo ético que mantiene que los sujetos, destinatarios o receptáculos de los principios, normas y valores morales, son las personas individuales separables. Creo que algunos liberales cometen el error de trasladarse insensiblemente desde el individualismo ético al individualismo ontológico o metodológico, y suponen que dado que las reglas morales han de inspirarse en la separabilidad de los individuos, el grupo social o la decisión colectiva sólo son concebibles o interpretables en términos individuales. Desde el punto de vista del comunitarismo se tiende a operar un deslizamiento inverso: Como se considera a la realidad humana como una entidad comunitaria distinta de, y anterior a, los individuos, se infiere de ello que el sujeto de la norma moral es la comunidad y el individuo sólo lo es derivativamente. Es decir, que a partir de un comunitarismo «ontológico» se desemboca en un comunitarismo «ético».

Aunque no falte quien haya afirmado que los tres planos que he distinguido se implican mutuamente, mi posición es, sin embargo, que una concepción de la ética y una concepción de la sociedad no tienen por qué tener tales implicaciones mutuas, $\mathrm{y}$, en particular, que una concepción liberal de la ética es compatible con una descripción comunitaria de la textura de la realidad humana. Separar de ese modo el aspecto descriptivo de la sociedad del aspecto normativo de la ética nos evita, para empezar, cometer un error al que tienden ciertas versiones del comunitarismo, y es el de considerar a las reglas y convenciones del grupo como normas éticamente justificadas sólo porque establecen de facto la cohesión grupal y cooperan a la inserción de los individuos. Creo, por el contrario, que afirmar que los individuos siempre interactúan coordinadamente no nos obliga a dar por buenas siempre sus pautas de coordinación. $\mathrm{Y}$ otro error que también es preciso evitar es el de suponer que porque el grupo tenga unas propiedades especiales que lo hacen irreductible a la pura suma de individuos, éstos, es decir, los individuos, no cuentan como tales; o lo que es lo mismo, tomar al grupo en cuanto tal como punto de partida no nos obliga a aceptar la idea de que los individuos sólo son definibles en términos de pertenencia al grupo. Por el contrario, los individuos son agentes con un grado de autonomía potencial mayor o menor, pero innegable; y pueden enfrentarse críticamente a las pautas grupales y poner en cuestión, aceptar o violentar el contenido de las mismas en medida muy relevante. A pesar de su inserción empírica en el grupo son conceptual y éticamente «separables», sin que, por reconocerlo así tengamos a mi juicio que compartir una teoría «atomista» 
de la realidad humana. El componente social y el componente individual de la realidad no son incompatibles ni se excluyen mutuamente.

Aclarado esto, es preciso todavía avanzar un paso más allá de la simple visión de la realidad humana como un grupo inmediato que pervive mediante una cohesión producida por convenciones sencillas y rutinarias. Siguiendo una tradición sociológica que se remonta a los trabajos de Tönnies o Cooley no podemos detener la consideración de esa realidad social en los grados incipientes y primitivos de la «comunidad» o el «grupo primario», con predominio de interacciones face to face y vínculos emocionales y tradicionales. Esto sería en todo caso un estadio o un momento, o un escalón inicial que, aunque puede operar todavía como modelo teórico para enfrentar algunos aspectos actuales de la sociedad, es, sin embargo, excesivamente limitado en su alcance interpretativo. Es preciso, como digo, dar un paso más hasta encontrarse con ese tipo de grupo humano que cuando se enfrenta a la necesidad de «actuar» (en el más amplio sentido de «actuar») como tal grupo crea un mecanismo para operar dentro de sí una división del trabajo grupal en virtud de la cual alguno o algunos de sus miembros son «destacados» para satisfacer esa necesidad grupal. Se suele hablar de propósitos o necesidades «comunes» del grupo para poner de manifiesto que lo que tal individuo o individuos llevan a cabo al actuar así es algo que, en principio, tiene relación con el grupo como tal y no con ellos como individuos miembros. O que sus actos son una función del grupo y no de sus planes individuales o sus preferencias personales. Todo grupo humano que tenga que mantener una actividad estable como tal necesita llevar a cabo dicha operación. En la tradición intelectual alemana de la teoría política esto era reconocido con toda claridad. Kelsen pensaba que era «una ley de la construcción de los organismos sociales» (Kelsen, 1977, pág. 56). Herman Heller lo afirmaba tajantemente: «No es posible que se mantenga en actividad la unidad colectiva de acción sin el obrar de un órgano que cuide de un modo consciente, tanto de determinar los fines como de su realización». (Heller, 1987, pág. 104.) Ahora bien, como el anterior, este punto de vista exige también una advertencia precautoria, porque aunque ni Kelsen ni Heller cometieron ese error, su uso frecuente de la expresión «órgano» puede inducir a caer en la tentación «organicista» de atribuir al grupo un «ser» o una naturaleza de «entidad» de la que los individuos destacados para realizar una tarea fueran simplemente «órganos» en un sentido similar al de la biología. Y no se trata de eso. Se trata sencillamente de dar respuesta a una situación 
en la que un conjunto de individuos interrelacionados por reglas se encuentran en la tesitura de tener que actuar como conjunto y no en términos de sus individualidades. Que, conceptualmente, pueda diferenciarse entre actos del conjunto y actos de los individuos no significa que al conjunto en cuestión se le atribuyan propiedades como las de un ser biológico o una entidad metafísica que actúa mediante miembros «ad hoc», extremidades u órganos, sean físicos o místicos. (Elías Díaz, 1966, cap. II.) No se trata, pues, de cuerpos místicos ni de entes biológicos de tipo alguno, sino de conjuntos de individuos en sentido estricto.

Lo que trato de mantener es que para diseñar un modelo teórico que nos pueda servir de punto de partida en el análisis de la democracia representativa es preciso a mi juicio, tener en cuenta esta suerte de operación de «simplificación» en virtud de la cual, a partir de un conjunto dado (el grupo humano total) se «extrae» un subconjunto que en cierto sentido sustituye significativamente al conjunto original. Tomando a préstamo, con todas las reservas que cabe suponer, el lenguaje matemático, podría decirse que en el conjunto-grupo humano se pone en marcha una ley de composición u operación interna en virtud de la cual se obtiene como resultado un subconjunto menos complejo que «equivale», reemplaza o hace las veces del conjunto anterior. Naturalmente, en qué consiste esa «operación interna», qué se pretende con ella, y a qué miembros del grupo base se aplica es algo que puede ser extremadamente variable y con gran diversidad de contenidos potenciales, arbitrarios o racionales. Si antes he recordado la idea de «división del trabajo social», en la que Kelsen insiste una y otra vez precisamente a estos efectos, es porque constituye un modo eficaz y general de expresar toda la gama posible de razones, causas y motivaciones que pueden impeler a un grupo humano a realizar esa o esas operaciones internas mediante las que se atribuye a uno o varios individuos la misión de actuar en lugar de la totalidad del grupo. A poco complejo que un grupo humano sea, surgen en torno a él objetivos y necesidades que fuerzan a dividir el trabajo mediante operaciones internas que atribuyen a algunos de sus miembros cometidos orientados a la satisfacción de esas necesidades y la consecución de dichos propósitos. La defensa o la agresión, la interacción con otros grupos, la organización interna de conductas a través de pautas generales, la persecución de objetivos económicos comunes, la protección frente a cambios o amenazas en el medio o cualquier otro curso de acción relativo al grupo en cuanto tal exige inmediatamente esa división del trabajo. Hasta tal punto que, por encima de ser empíricamente imposible encontrar un 
grupo humano mínimamente complejo que no haya operado en su seno tales divisiones, resulta también conceptualmente insuficiente definirlo sin tenerlas en cuenta. Por eso, mi sugerencia es que, para hablar del concepto y fundamento de la representación política, construyamos un modelo de acuerdo con el cual nos representemos al grupo humano como un conjunto de individuos que han realizado una operación interna de división del trabajo para hacer posible su actuación como grupo, en lugar de articular el modelo teórico subyacente en base a la concepción del grupo humano como conjunto desagregado de individuos.

Dejando a un lado la metáfora matemática, lo que propongo es que, cuando nos pongamos a hablar de representación política lo hagamos a partir de un modelo de grupo humano con esas características. Sólo de esta forma podremos eludir con éxito el problema que antes mencionaba de la distorsión argumental que exige pasar de la justificación de la democracia directa a la justificación de la democracia representativa a través de la cláusula de imposibilidad. Mi propuesta también puede verse cómo una afirmación de que ese paso no es necesario si empezamos a construir sobre una base o un modelo no atomista. Ahora bien, semejante propuesta parecería ser una presa fácil ante dos objeciones fundamentales. La primera de ellas aduciría que, aun en el supuesto de que hubiera evidencia empírica al respecto, los modelos teóricos de los que se parte no tienen por qué incorporar abstractamente los rasgos empíricos de la realidad. La segunda, más importante, es que se cometería una clara petición de principio si se tratara de justificar la representación política mediante el procedimiento de recurrir a ciertos rasgos empíricos de la realidad para proponer un modelo de grupo humano en el que la «representación» del grupo por subconjuntos pertenecientes a él sea una característica necesaria o conceptual, una característica definitoria del grupo humano mismo. Sería un caso obvio de introducción subrepticia de la conclusión en las premisas. Trataré de contestar a ambas. Que hay evidencias históricas y sociales en favor del modelo propuesto parece indudable. Los antropólogos contemporáneos (vid., por ejemplo, Service, 1984, y la bibliografía allí citada) mantienen que incluso la sociedad primitiva «igualitaria» y pequeña, no es que carezca en sentido estricto de esa traslación de actos grupales a individuos seleccionados para llevarlos a cabo, sino que articula, cuando lo exige una necesidad o un propósito del grupo, un mecanismo de liderazgo inestable basado en la competencia y destreza particular de alguno de sus miembros que es el que, en nombre del grupo y en un momento dado, lleva a cabo el trabajo de acción, mediación, 
relación exterior o sanción preciso para satisfacer aquella necesidad o cumplir el propósito. Después de ello tal liderazgo contingente desaparece. En un estadio ulterior de complejidad y organización el liderazgo tiende a institucionalizarse y constituye un cargo normado, como sucede en las llamadas «sociedades de jefatura», que son a su vez el estadio inmediatamente anterior a lo que hoy conocemos como sociedades políticas o Estados. Si esto es así, construir sobre la base de un modelo de grupo humano que ignore esa necesaria diferenciación de roles para las acciones comunes que identifica al grupo resulta metodológicamente sorprendente. Ciertamente los modelos no tienen por qué describir la realidad ni dar cuenta de ella pero si quieren ser instrumentos de análisis y solución de ciertos problemas no pueden ignorar los rasgos básicos del marco empírico en el que se dan esos problemas. Cuando lo hacen así es cuando surgen las cláusulas de imposibilidad, porque no proponen soluciones «ideales» a las que es más o menos difícil ir acercándose; es que proponen directamente soluciones imposibles. Tratar de fundamentar la democracia representativa a partir de «un cierto número de personas» que «se proponen» tomar una decisión desemboca en una solución imposible. Simplemente, el problema de la representación política pertenece a un mundo que no puede ser alcanzado por ese modelo.

Respecto a la segunda objeción, es preciso hacer notar que la presente propuesta no pretende justificar o fundamentar la necesidad social de esa diferenciación de roles. Tal cosa se da por supuesta. Se trata más bien de justificar una forma de satisfacer dicha necesidad, como es la representación política a través de elecciones libres. Supuesto que, por definición, el grupo humano sea un conjunto en el que, mediante cierto procedimiento, se produce una diferenciación de ciertos roles y una adscripción de tales roles a ciertos individuos, la pregunta es qué fundamento puedan tener los distintos procedimientos que se siguen para llevar a cabo esa operación. Y, en particular, tratándose de roles cuyo contenido es actuar para alcanzar objetivos «políticos» del grupo como un todo, qué fundamento puedan tener los procedimientos para adscribirlos. Porque el procedimiento para llevar a cabo esa adscripción ha sido históricamente muy heterogéneo y variado: Pertenencia a una familia del grupo primogenitura dentro de ella, posesión de riqueza, posesión de habilidades técnicas, condición religiosa, conquista... y elecciones. Y, dentro de las elecciones, por supuesto, una gran diversidad de posibilidades. Por todos estos caminos un grupo social complejo ha podido segregar de sí mismo a ciertos individuos que actúen en su nombre 
en la persecución de algunos objetivos del grupo. Y todos esos individuos, por el hecho de actuar en nombre de, o para el interés del grupo, puede decirse en un sentido muy lato que «representan» al grupo. Pero, como es evidente, no lo representan del mismo modo. En la segunda parte de este trabajo trataré de profundizar en esta cuestión.

\section{II}

Si las consideraciones anteriores son correctas, nos encontramos con que aun en un modelo muy simplificado de grupo humano, hemos de tener en cuenta el fenómeno de que algún o algunos individuos emiten pautas para los miembros del grupo y desarrollan acciones en nombre del grupo que afectan o pueden afectar a los intereses de dichos miembros. Esos individuos hacen para el grupo cosas tales como tomar decisiones, mediar conflictos, relacionarse con grupos externos, afrontar amenazas del exterior, imponer sanciones, etc... Además, dichos individuos toman usualmente decisiones que llevan consigo la utilización de la fuerza sobre miembros del grupo. El grupo, como hemos visto, se define por las pautas de coordinación que gobiernan las interacciones, y aunque tales pautas sean seguidas generalizadamente, necesitan también de algún tipo de sanciones que las refuercen (Barry, 1979, pág. 173). Administrar esas sanciones suele ser tarea de ese conjunto de individuos. La cuestión es, entonces, cómo establecer un procedimiento razonable para determinar qué individuos van a tener adscritos roles tan importantes y en qué condiciones. Y la respuesta moderna a esa cuestión es la teoría de la representación.

Mientras que criterios como la herencia, la propiedad o la pura fuerza parecen decididamente insuficientes y caprichosos para atribuir esos roles, la idea de que los que los portan han de ser «representantes» de los demás miembros, ha acabado por imponerse. Hasta los dictadores más arbitrarios se presentan como la voz del «verdadero» pueblo. Pero la multivocidad de la expresión «representación» es muy intensa y ha sido analizada con gran detenimiento. Siguiendo trabajos ya clásicos (Pitkin, 1967) pueden distinguirse en ella al menos cinco significados diferenciados:

1. Representación como símbolo, que se refiere a imágenes, banderas, escudos, instituciones, etc..., como esquemas simbólicos que tratan de remitirnos mediante un complejo proceso intelectivo-sensorial 
a otras realidades como la nación, el pueblo, el partido, etc...

2. Representación como reproducción a escala de la realidad social. Es muy eficaz aquí recurrir a la imagen del «reflejo», de la posibilidad de que la sociedad se vea retratada o reflejada en un órgano como en un espejo o como en una fotocopia reducida. Este es el criterio que se utiliza cuando se critica como no representativos a ciertos órganos que carecen de integrantes pertenecientes a cierto sector social, sexo, profesión, status, etcétera.

3. Representación como cuidado de intereses, como actuación en interés de otros. En toda realidad social se dan grupos, organismos o colectivos que se definen por su dedicación al cuidado de ciertos intereses, incluso que se constituyen para desarrollar ese cuidado, como los sindicatos o los grupos de presión.

4. Representación como autorización para decidir, que es, quizá, la extensión de la idea jurídica de poder, apoderamiento, mandato, etc... y de acuerdo con la cual el representante o representantes son investidos mediante un procedimiento con el poder o facultad de tomar decisiones, emitir normas, establecer directrices, etc...

5. Representación como disposición a responder (responsiveness), es decir, como sometimiento periódico de los propios actos ante alguien a quien afectamos con esos actos. Se usa con frecuencia cuando en el lenguaje político se identifica al gobierno representativo como aquel en el que se responde periódicamente ante los electores.

De estos cinco significados posibles de «representación», hay dos, el primero y el segundo, que son puramente descriptivos; los otros tres son normativos (Digss, 1968). En los dos primeros el representante representa porque es algo: un símbolo o un reflejo. En los demás, el representante representa porque tiene competencia o poder para hacer algo, o porque debe hacer algo. Además es preciso hacer notar que de los cinco sentidos posibles de la expresión, sólo en dos de ellos (representación como autorización y representación como disposición a responder) aparece como condición necesaria de la representación la actuación de los «representados». En el primero de ellos facultando al representante para actuar, y en el segundo pidiéndole cuentas. Estas distinciones son fundamentales; sin embargo, en el lenguaje político cotidiano, e incluso en el lenguaje constitucional, suelen ignorarse.

Alguien que sea el «representante-símbolo» de una comunidad, como lo es el Rey del Estado Español (art. 56 Const. Española), puede no ser representativo en el sentido de reflejo, ni 
estar autorizado para decidir, ni cuidar de ningún interés en particular, ni responder ante nadie. La función simbólica que llevan adherida algunas personas, instituciones u objetos nos hace decir en el lenguaje político que «representan» al Estado, al pueblo, a la nación, etc... Y esta función cumple sin duda algunas tareas políticas de importancia: identificación y cohesión de los miembros del grupo, integración política, transferencia de frustraciones empíricas, etc... Pero es obvio que no decimos de esos símbolos que son «representativos» del pueblo o de la nación. Nadie pretendería esto.

Más problemático resulta analizar el segundo sentido descriptivo de la expresión aplicado a la política, es decir, aquel según el cual los representantes políticos «representan» en el sentido de que reproducen o reflejan la realidad social. Aquí el equívoco es cotidiano y se acusa incesantemente a órganos de decisión y a instituciones políticas de falta de representatividad porque no incorporan algunos componentes de la realidad social (Mujeres, trabajadores, estudiantes, etc...). Y ciertamente los órganos de decisión política con frecuencia no «reproducen» la realidad en aspectos que todos consideramos relevantes (por ejemplo, raramente los parlamentos tienen más de un 10 por 100 de mujeres o un 5 por 100 de obreros, es decir, raramente son «representativos» en este sentido). La cuestión es, en efecto, si serían más «representativos» si reprodujeran fielmente esa realidad. $\mathrm{O}$, lo que es lo mismo, si la representación política es una representación reflejo de la realidad. La respuesta afirmativa se encuentra inmediatamente frente a algunas serias objeciones. En primer lugar este método de representar políticamente tiene algunas dificultades severas para incorporar la voluntad de los representados. Según él una buena «muestra» estadística, es decir, un órgano de decisión configurado con arreglo a métodos «demoscópicos» sería seguramente más representativo que un órgano integrado por miembros elegidos por los representados. Como se ha propuesto no hace mucho tiempo, un procedimiento de sorteo para elegir los miembros de un Parlamento sería muy deseable por lo representativo que resulta (Burnheim, 1985). Por el contrario, un método que, como las elecciones, dé un peso sustancial a la voluntad de los representados suele arrojar un resultado poco «representativo», es decir, suele producir una «muestra» muy deficiente. La razón de esa incompatibilidad frecuente entre los resultados de la representatividad-reflejo y los de la representatividad-elección es que la primera propone un criterio material para formar los órganos de decisión política, mientras que la segunda propone un criterio procedimental, y la 
distinta naturaleza de los criterios es lo que explica la posible heterogeneidad de los resultados. Ello nos pone en una disyuntiva interesante, porque subrayando este sentido de «representatividad» podemos acabar por postergar la voluntad del «demos» para representar «fielmente» al «demos». No otra cosa significaría el introducir criterios paraprocedimentales de representatividad en la decisión colectiva. Pero cuando la voluntad de los representados tiende a pasar a un segundo plano nos estamos deslizando hacia algún tipo de lo que se ha llamado «representación virtual»: Una suerte de fenómeno misterioso, místico, hace al representante incorporar los deseos, intereses y preferencias de los representados aun en ausencia de pronunciamiento por parte de éstos.

La segunda objeción es que la representatividad-reflejo no puede resolver fácilmente el problema de identificar los criterios que señalan qué es lo que hay que reflejar en el órgano representativo de la realidad social. Cualquier rasgo de los que definan a un sector del «demos» sería un candidato posible, y la pretensión de incluirlos todos abocaría a una repetición (y no una representación) de la realidad. Pensemos en el sexo, el status social, la profesión, las convicciones religiosas, las características físicas, etc... La diferenciación entre rasgos relevantes y rasgos irrelevantes suele llevar consigo enojosos problemas de justificación.

La propuesta de integrar los órganos decisorios proporcionalmente, es decir, en función de la proporción de votos que cada opción ha obtenido en las elecciones puede ser vista como una muestra de la influencia que esta teoría de la representación ha ido adquiriendo, pero también admite otras interpretaciones. En todo caso lo que parece evidente es que no resulta del todo satisfactoria porque también los parlamentos proporcionalmente formados son objeto de crítica por poco «representativos». Además, no hace sino desplazar el problema a un estadio ulterior, pues si esta propuesta se llevara a sus últimas consecuencias, entonces todos los gobiernos nombrados por esos parlamentos tendrían que ser gobiernos de coalición para ser «realmente» representativos de la proporción de asientos de cada fuerza. De todas formas, la opción por la representación proporcional sigue girando en torno a la decisión de los electores y no a la presencia de sus rasgos en el resultado.

La tercera acepción de la expresión «representación»se refiere a la actuación en interés de otros, al cuidado de los intereses del representado. Según ella serían representantes aquellos cuya actuación pudiera ser interpretada como defensa o protección de los intereses de otro. Y la representación política como un actuar con una particular sensibilidad hacia los intereses de los representados, 
que se manifiesta en una conducta compleja que busca una cierta congruencia entre las preferencias de los electores y las decisiones de los representantes, que facilita una serie de servicios y mejoras a individuos o grupos pertenecientes al distrito electoral, que distribuye en él alguna porción del presupuesto público, que, en fin, establece con el distrito unas relaciones simbólicas de complicidad y confianza que fomentan el apoyo al representante. Esta relación tan compleja e indeterminada es la que da contenido a ese actuar «en interés de...» que, según algunos teóricos, es la representación política (Eulau H. y Karps P., 1977).

Este punto de vista tampoco carece de dificultades. Dejando a un lado la vieja «representación de intereses» que no es sino un supuesto de la posición anterior, el problema de la relación representante-representado subsiste en él, porque en efecto, puede concebirse en el ámbito de la política un «actuar en interés de...» que haga caso omiso de la voluntad de los representados. En el ámbito del derecho privado eso es admisible, porque la institución de la representación funciona con frecuencia respecto de menores o de incapaces (Díez Picazo, 1979), pero en el ámbito de la política no parece que tenga justificación alguna el definir la representación sin prever un lugar destacado en la misma para las preferencias expresadas de los representados. Puede de hecho haber ciertas decisiones políticas (las llamadas decisiones políticas paternalistas) en las que el interés del destinatario sea más relevante que su voluntad, pero definir la representación política en esos términos parece inadecuado. Además en el ámbito de la política nos salen al paso a veces personas, organizaciones y colectivos (los lobbyists, grupos de presión, sindicatos, etc...) cuya función arquetípica es precisamente la de «actuar en interés de...» alguien y que, sin embargo, no consideramos representantes políticos de ese alguien, sino precisamente agentes que se mueven al margen, o en los aledaños de la representación política.

Más grave es, sin duda, una consecuencia implícita en este punto de vista con relación a la concepción de la democracia representativa que de él se deriva. Si la representación política no es más que un mecanismo mediante el cual se concentran en un órgano de decisión los intereses de los distintos segmentos sociales a través de unos voceros cuya función consiste en cuidar de cada uno de esos intereses, entonces la democracia aparece directamente como un proceso de negociación incesante de intereses a la búsqueda de una solución de compromiso, y el corporatismo no sería sino una extensión de la democracia. Es lo que 
se ha llamado la democracia «consociacional». Sin pretender entrar en un tema de tal envergadura, diré tan sólo que, desde el punto de vista de la justificación de la democracia, esa perspectiva desemboca en un callejón sin salida.

Desde otro ángulo surge una nueva dificultad que en mi opinión subyace a la secular controversia entre mandato imperativo e independencia del representante (Pitkin, 1967). Me refiero a la noción de «interés general», que en una concepción de la democracia como negociación de intereses particulares encuentra difícil acomodo y que conduce necesariamente a imposibilitar la noción de independencia del representante político y a fortalecer la teoría del mandato imperativo. Porque, en efecto, no se puede ver muy claramente por qué el representante político, si lo es de un segmento de intereses que llevan consigo una determinada fuerza, debe abandonar, aunque sólo sea parcialmente, su defensa en aras de algunas de las pautas generales de carácter prudencial o moral que presumiblemente informan la idea de interés general (Bardach, 1981). Si su función es cuidar de ciertos intereses, entonces está sujeto a ellos, y cuando, independientemente, los defrauda en todo o en parte apelando a criterios éticos, ha dejado de cumplir su función. Lo que significa que, desde este punto de vista, la justificación moral de la institución de la representación política es, en el mejor de los casos, contingente y relativa al tipo de intereses que se cuidan.

Estos y otros argumentos invitan a no aceptar la teoría de la representación política como cuidado de intereses, por mucho que sea quizás la teoría dominante. La necesidad de incluir en la idea política de representación la presencia decisoria de los representados se pone de manifiesto incluso en el seno de esa misma teoría cuando Mill propone que se asuma como evidente que cada uno es el más competente para saber cuáles son sus intereses y, por tanto, para decidir sobre ellos. Entonces, al margen de la solidez de esta aseveración, nos encontramos que lo que cuenta en realidad no es el interés de cada uno, sino su decisión al respecto, ya que no podemos entrar a dilucidar si su decisión es o no es acorde con su interés por pura incompetencia. Lo importante, pues, no es quién cuida de mis intereses, sino quién decido yo que lo haga y ello nos sitúa en las dos últimas teorías de la representación política, la teoría de la autorización y la teoría del sometimiento periódico al voto de los representados.

La teoría de la autorización gira, en efecto, en torno a los representados, porque mantiene que los representantes políticos son designados o nombrados, es decir, son creados a través de las elecciones. El representante político es cualificado como tal 
para realizar actos y tomar decisiones mediante la autorización electoral. El problema de esta posición es determinar en qué consisten esos presuntos actos de autorización, designación o nombramiento, y surge básicamente por la existencia de una cierta inclinación tácita, poco crítica, a aplicar a la idea de representación un modelo de corte jurídico-contractual. La suposición usual es que, mediante su voto, que es una especie de acto de voluntad negocial, los electores apoderan a los agentes políticos para que tomen decisiones normativas. En virtud de un acto de consentimiento como es el voto, los representantes están facultados para vincular con sus decisiones a los electores. Este planteamiento ha sido sometido a una severa crítica. En primer lugar se ha cuestionado su pretensión justificatoria (Pateman, 1985). Se afirma en esta línea que el modelo de la «promesa», el «consentimiento» o el «contrato» no sirve para justificar las acciones de los representantes ni sus decisiones porque no puede ser aplicado al hecho de votar. Votar no es prometer nada, ni consentir nada, ni contratar nada, y si la fuente o el fundamento de las obligaciones es la promesa o el consentimiento, entonces el hecho de votar no fundamenta obligaciones de tipo alguno y, en particular, votar no hace vinculantes las decisiones del representante político. Por otra parte, se ha criticado este enfoque por su vaciedad, por ser puramente formal, arguyendo que el acto consensual de autorizar nada nos dice sobre la actividad cotidiana del representante, sobre la naturaleza de la actuación que lleva a cabo, que es, a fin de cuentas, lo que da contenido y sentido a la cualidad de ser representante (Pitkin, 1967).

La primera de esas críticas, realizada en el marco de un análisis de la obligación política, se refiere sobre todo a la fundamentación de la vinculatoriedad de las normas emitidas por los representantes, o, por decirlo más concisamente, al fundamento de la presunta obligación de obedecer el derecho en ciertos supuestos, que es un tema diferente del que nos ocupa ahora. La crítica, en todo caso, podría eludirse con cierta facilidad si evitamos identificar los actos de los representados o votantes como actos de voluntad negocial, promesas o consentimientos expresos o tácitos a las normas. Por otra parte, como es bien sabido, la cuestión de quién emite legítimamente normas (es decir, la cuestión de quién gobierna) y la cuestión del fundamento de la vinculatoriedad de las normas (que puede presentarse como una versión de la cuestión de cómo se gobierna) son perfectamente diferenciables. Responder a esta segunda cuestión no supone necesariamente entrar en la primera que es, en rigor, la que atañe al concepto y justificación de la representación política. 
La segunda crítica, ampliamente compartida hoy, vuelve a plantear el problema de la procedimentalidad y la materialidad de los criterios de identificación y fundamentación de la representación política. Si ser representante político consiste en realizar una cierta actividad de una cierta naturaleza, entonces cualquiera que realice dicha actividad es representante político material al margen de si se encuentra procedimentalmente nominado para hacerlo. En sentido inverso un agente designado de acuerdo con las reglas del procedimiento que no realizara la mencionada actividad no sería, en rigor, representante político. Por tanto, el procedimiento, como mecanismo puramente formal no puede constituirse en elemento definitorio de la institución. El error de este acercamiento crítico, que supone en definitiva el desahucio de las elecciones del espacio de la representación política, es doble. Por un lado, una visión de la idea de «procedimiento» (o, en sus propios términos, «autorización», «designación», etc...) como un artilugio mecánico de carácter puramente formal carente en absoluto de virtud. El sorteo podría ser un ejemplo de dicha visión. A cualquiera le puede caer en suerte ser representante sin que tal cosa tenga, efectivamente, ningún significado moral. Por otro lado, la suposición infundada de que un mecanismo procedimental sólo puede arrojar un resultado «formal» y nunca «material».

Al primer error se le puede contestar que, si es cierto que algunos tipos de procedimientos encaminados a la satisfacción de cierta necesidad social pueden ser neutros, como el sorteo, o incluso rechazables por arbitrarios (ordalías, etc...), hay otros que, en cambio, incorporan algunos rasgos procedimentales cuya naturaleza racional o moral queda fuera de toda duda. Y, por lo que respecta a la representación política, si la designación de representantes se realiza mediante un procedimiento que incorpora rasgos como la igual consideración de los afectados (Still, 1981), la libertad de acción y decisión, un amplio intercambio de opiniones y el principio mayoritario, es difícil decir que ese procedimiento tiene el mismo significado «formal» que una designación caprichosa emanada del más fuerte o basada en el color de las vísceras de una cabra. Dudo mucho que, incluso conceptualmente, no consideremos más representantes políticos a los primeros que a los segundos, al margen de que el método de designación nos diga o no nos diga nada sobre la «actividad» que van a realizar.

El segundo error de ese punto de vista estriba en suponer que un rasgo procedimental no puede producir un resultado «material», o, en el presente caso, que el procedimiento formal de designación 
de representantes no tiene relación alguna con la «actividad» de los representantes. Esto nos lleva a la última de las acepciones de representación política mencionadas: aquella que subraya la disposición a rendir cuentas de los representantes como rasgo definitorio de la institución. En realidad, la teoría que trata de circunscribir la idea de representación a una actividad consistente en la disposición, sensibilidad y cuidado hacia los problemas de los representados no nos dice nada acerca de cómo puede insuflarse semejante actitud en los agentes políticos. El rasgo procedimental de rendir cuentas periódicamente a través del sometimiento al voto de los representados, a pesar de su mero carácter formal, es decisivo a estos efectos. La teoría de la «desautorización», como reverso de la teoría de la «autorización», completa la visión procedimental de la representación política de un modo que al mismo tiempo es eficaz para producir una actuación material determinada en los representantes. De hecho, este sometimiento periódico al voto, esta decisión periódica de los electores sobre la gestión ha sido uno de los componentes teóricos más interesantes de la concepción económica de la democracia (Downs, 1975) precisamente porque subrayaba la conexión funcional entre un rasgo formal del procedimiento y un resultado material. La periodicidad en la rendición de cuentas tiende a presionar al agente político para que actúe de forma que su cliente potencial, con su moneda de pago, es decir, con su voto, no «se vaya a la competencia», y eso es equivalente a suponer que con su actividad tratará de ser sensible y perceptivo hacia los problemas de sus representados. Si esto es así, entonces, la característica de responder periódicamente ante los electores tiene que ser un rasgo básico de la teoría de la representación. De hecho, como antes he sugerido, no es más que el envés de su otra cara: la designación de los representantes mediante un procedimiento decisorio en que participen los representados. Ambas cosas configuran a la representación política como una institución compleja de naturaleza esencialmente procedimental, y no, como se ha pretendido, como una institución que deba definirse primariamente por sus rasgos materiales.

\section{III}

Para terminar quisiera arriesgar una propuesta normativa sobre la justificación de la representación política democrática de un modo lo suficientemente directo y provocativo como para que pueda suscitar la discusión. Es obvio que las aserciones que 
van a continuación necesitarían precisiones, matices y complementaciones muy relevantes. Es igualmente obvio que demandan un amplio y profundo desarrollo. Pero como línea argumental y de orientación creo puede ser útil ponerla a discusión. Estas son sus afirmaciones:

a) El grupo social humano se define por la existencia en su interior de pautas y reglas estables de interacción y coordinación que necesitan de algún tipo de sanciones que las refuercen.

b) Como tales reglas no parecen estar dadas de antemano, ni inscritas en el código genético de la especie, es necesaria la existencia de decisiones sobre su creación, aplicación $\mathrm{y}$ modificación, $\mathrm{y}$, por tanto, de un procedimiento para tomar esas decisiones.

c) El grupo social humano satisface sus necesidades y desarrolla sus acciones mediante mecanismos de división del trabajo social de acuerdo con los que se atribuyen a algún individuo o grupo de individuos miembros los roles sociales precisos para satisfacer las correspondientes necesidades y desarrollar tales acciones.

d) La institución de la representación política es un mecanismo de este tipo, cuya tarea específica es satisfacer la necesidad social de designar al individuo o individuos que emitan las decisiones sobre la creación, aplicación y modificación de las reglas y pautas mencionadas en $a$ ).

e) Una institución social se justifica moralmente si cumple con los siguientes requisitos máximos: 1) Reconoce a todos los afectados igualmente como «agentes morales». 2) Atribuye a cada uno el máximo grado de libertad compatible con una igual libertad para los demás. 3) Trata a todos por igual.

f) Una institución representativa es justa si: 1) Se basa en el sufragio universal y reconoce a todos y cada uno capacidad como agentes en el proceso de decisión electoral. 2) Articula un sistema normativo de libertades de expresión, voto, propuesta, etc... lo más amplio posible. 3) Produce una discusión libre y equitativa de las opciones. 4) Concede el mismo valor decisorio a cada voto, es decir, se rige por el criterio de la mayoría. 5) Se reproduce con una periodicidad razonable.

g) Una institución representativa justa es la forma más congruente de satisfacer la necesidad social mencionada en $d$ ).

h) Los miembros de una sociedad o grupo social humano tienen un deber moral «prima facie» de participar en el funcionamiento de una institución representativa justa.

i) Los individuos elegidos a través del funcionamiento de 
una institución representativa justa son agentes políticos con poder legítimo para tomar las decisiones normativas mencionadas en $a$ ).

j) Las reglas y pautas sociales emanadas de los representantes políticos designados mediante un mecanismo que cumpla los requisitos mencionados en f) están dotadas de una justificación ética inicial, en el sentido de que, si no entran en conflicto con exigencias morales más fuertes, tienen una pretensión fundada de obligar y justifican, en su caso, la imposición de sanciones.

k) Quien se opone a tales normas alegando razones morales ha de soportar la carga de la prueba.

\section{BIBLIOGRAFÍA}

Barry, Brian, «Is Democracy Special?», en Philosophy, Politics and Society, Fifth Series, Oxford, 1979.

Bardach, «On Representing the Public Interest», en Ethics, 1981.

Böckenforde, Ernst-Wolfgang, «Democrazia e Rappresentanza», Quaderni Constituzionali, anno, V, núm. 2, agosto, 1985.

Burnheim, J., Is Democracy Possible?, Oxford. Polity Press, 1985.

Dahl, Robert, «Procedural Democracy», en Philosophy, Politics and Society, Fifth Series, Oxford, 1979.

Díaz, Elías, Estado de derecho y sociedad democrática, Madrid, 1966.

Díez Picazo, Luis, La representación en el Derecho privado, Madrid, 1979.

Diggs, Practical Representation, Nomos X, Representation, New York, 1968.

Downs, Anthony, Teoría económica de la democracia, Madrid, Aguilar, 1973 (ed. orig. 1971).

Ethics, vol. 91, núm. 3, April, 1981.

Eulau, H., y Karps, Paul, «The Puzzle of Representation: Specifying Components of Responsiveness», en Legislative Studies Quarterly, 2 (1977), recogido en Fisichella, 1983.

Farrell, Martín D., La democracia liberal, Abeledo Perrot, Buenos Aires, 1988.

Fisichella, Domenico (a cura de), La Rappresentanza Politica, Milano, 1983.

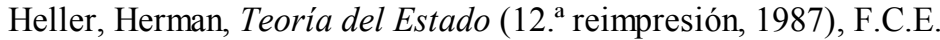

Honoré, Antony, What is a Group?, ARSP, vol. 1975 LXI/2.

Kelsen, Esencia y valor de la democracia, Madrid, 1977.

Montesquieu, De l'Esprit des Lois, XI, 6.

Mill, John S., Consideraciones sobre el gobierno representativo, Ed. Tecnos., Madrid, 1965 (ed. orig. 1861).

Nino, Carlos S., «Liberalismo versus Comunitarismo», Revista del Centro de Estudios Constitucionales, 1988, núm. 1.

Nomos X., Representation, New York, 1968.

Pateman, Carole, The Problem of Political Obligation, Oxford, 1985. 
Pitkin, Hanna, El concepto de representación, Madrid, C.E.C., 1985 (ed. orig., 1967). Service, Elman R., Los orígenes del Estado y la civilización, Alianza Ed., Madrid, 1984.

Singer, Democracia y desobediencia, Ariel, Barcelona, 1985.

Still, «Political Equality and Election Systems», Ethics, 1981. 